\title{
ELEMENTOS SOBRE A CONFIGURAÇÃO DO CAMPO DAS ATIVIDADES FÍSICAS PARA IDOSOS NO BRASIL
}

Recebido em: 18/07/2014

Aceito em: 10/03/2015

\author{
Silvio de Cassio Costa Telles \\ Universidade Federal do Rio de Janeiro - UFRJ \\ Universidade do Estado do Rio de Janeiro - UERJ \\ Rio de Janeiro - RJ - Brasil \\ Rômulo Meira Reis \\ Universidade do Estado do Rio de Janeiro - UERJ \\ Rio de Janeiro - RJ - Brasil \\ Edmundo Drummond Alves Junior \\ Universidade Federal Fluminense - UFF \\ Rio de Janeiro - RJ - Brasil \\ Ludmila Mourão \\ Universidade Federal de Juiz de Fora - UFJF \\ Rio de Janeiro - RJ - Brasil
}

RESUMO: Com o passar dos anos, a relação entre o idoso e a atividade física se tornou extremamente comum na sociedade. A mídia, o saber médico e o Estado propagam a importância de um estilo de vida ativo, afeto ao lazer, que potencializa as chances de longevidade. Este estudo buscou compreender como o campo das práticas de atividades físicas para os idosos se configurou no Brasil. Através de quatro entrevistas não estruturadas, do tipo guiada, construímos uma versão para o processo de gênese das práticas de atividades físicas para idosos. A Teoria do Campo de Pierre Bourdieu possibilitou analogias e interpretações das prováveis influências entre diversos campos sociais, primordialmente com o campo internacional. O período compreendido entre 1960 e 1980 foi o recorte temporal utilizado. Observou-se que a influência dos campos econômico, político, da saúde e educacional, em maior ou menor escala, acabou por forjar o campo da prática de atividade física pelo idoso na sociedade brasileira.

PALAVRAS CHAVE: Idoso. Atividade Motora. Atividades de Lazer.

\section{THE CONFIGURATION OF PHYSICAL ACTIVITIES FOR SENIORS IN BRAZIL}

ABSTRACT: Over the years the relationship between the elderly and physical activity has become extremely common in society. The media, medical knowledge and the State 
spread the importance of an active lifestyle, related to leisure, which enhances the chances of longevity. This study investigated how the field of practice of physical activities for seniors is set in Brazil. Through four guided unstructured interviews, we built a version for the genesis process of physical activities practice for seniors. Pierre Bourdieu's Field Theory led to analogies and interpretations of the likely influences between different social fields, primarily with international field. The study considered the time frame period between 1960 and 1980. The results showed that the influence of economic, political, health and educational fields, to a greater or lesser extent, eventually forged the field of physical activities practiced by the elderly in Brazilian society.

KEYWORDS: Aged. Motor Activity. Leisure Activities.

\section{Introdução}

Ao observamos o homem ao longo de sua história, percebemos que no século $\mathrm{XX}$ avançamos quanto às possibilidades que se referem ao aumento da expectativa de vida. Certamente, o progresso das ciências médicas atuando na prevenção, tratamento e controle de doenças, as melhorias das condições sociais, políticas, econômicas e a adoção de um estilo de vida mais saudável são fatores importantes para confirmar que nunca vivemos tanto como agora e por isso começamos a almejar um modo de vida distinto do que até então era buscado. Agora, não basta apenas envelhecer.

A atenção a uma parcela da sociedade - os idosos - ganhou status no rol das agendas sociais, políticas e científicas. Segundo Alves Jr. (2004), o mito da eterna juventude surge no século XX como uma resistência à velhice, apoiado por estratégias fundamentadas em pesquisas científicas como fruto de uma política específica da construção de um modo de vida na velhice.

Antigamente só se parava de trabalhar para morrer. Agora, existe um período entre o final do tempo de trabalho e a morte. O que fazer com esse "meio tempo" foi a grande interrogação. Não se morre mais no "seio" da família, mas em asilos, hospitais ou mesmo sozinho em casa. 
Segundo Melo e Alvez Jr. (2003), o lazer é um fenômeno moderno que surge da artificialização do tempo de trabalho, decorrente das mudanças provenientes da Revolução Industrial. Essa mudança forjou a carga horária do trabalhador, a qual, com o passar do tempo, foi sendo reduzida devido a intensas tensões entre a classe trabalhadora e os detentores dos meios de produção. Ainda fruto dessas tensões, a aposentadoria foi outra conquista que acabou também por alterar o modo como as pessoas utilizariam o período da vida entre o fim da jornada de trabalho e a morte.

Assim, o estilo de vida dos novos aposentados passou a ser regulado pelo Estado e por profissionais da saúde médicos, gerontólogos, geriatras e professores de educação física, os quais, tal como uma pastoral, passam a catequizar os idosos para que ficassem ativos o maior tempo possível. Cabe ressaltar que articulações entre diversos setores, como os da saúde, econômico, educacional e político e não somente as atuações dos profissionais das áreas citadas, passam a desencadear a possibilidade de um envelhecimento ativo e, acima de tudo, saudável.

Werneck (2000) discute que as mudanças no estilo de vida muitas vezes atendem mais às necessidades dos próprios profissionais do às de seus utilizadores. As estratégias do marketing de mercado são desenvolvidas para criar necessidades de consumo que acabam por serem inculcadas nas pessoas, impondo-lhes novos padrões de vida.

A interação de processos multifatoriais começava, portanto, a tornar-se fundamental, implicando que as relações entre os diversos campos que englobam a vida do idoso desencadeassem um novo habitus ${ }^{1}$. A atividade física, o esporte e o lazer, baseados nesse novo paradigma, passaram a ser apontados como importantes veículos

\footnotetext{
${ }^{1}$ Conceito que define habitus como uma gênese social dos esquemas de percepção, pensamento e ação.
} 
para o aprimoramento da qualidade de vida do idoso, ao mesmo tempo em que se reconhecia ser inviável desenvolver estilos de vida saudáveis sem a existência de uma sinergia entre outros fatores relacionados às condições básicas de vida dos indivíduos, como saneamento básico, emprego, moradia, saúde, dentre outros (FARINATTI; FERREIRA, 2006).

Ao longo do século XX, uma transformação possibilitou uma nova atitude por parte dos idosos no tocante à própria concepção de sua existência. Por acharem que as energias gastas com atividades não apresentavam significância àquela época, mantinham-se sedentários no intuito de viver mais (TELLES; MOURÃO, 2006).

Internacionalmente transformações sociais iniciadas na Europa nos anos de 1950 começavam a consolidar um espaço para a inserção do idoso. Em 1973 é criada a Universidade da Terceira Idade em Toulose, na França, dando a entender que acontecimentos que envolviam idosos em diferentes campos já faziam parte das políticas públicas (ALVES JR., 2004).

O estudo de Telles e Mourão (2006) acumula pistas sobre a importância das décadas de 1960 e 1970 como um período fértil no processo de legitimação dos estudos e ações destinados à prática de atividades físicas para os idosos em nosso país. Este estudo traz algumas evidências sobre a importância do SESC (Serviço Social do Comércio) e suas ações precursoras nessa área, ainda em 1963, bem como revela as ideias fundadoras de um artigo publicado em 1968, que pela primeira vez comenta ganhos de hipertrofia em trabalho de força com idosos. Até então, sugestões para se alcançar a longevidade surgiam no escopo do texto, contudo, para o indivíduo já idoso, as indicações eram baseadas em opiniões empíricas ${ }^{2}$.

\footnotetext{
${ }^{2}$ Para ratificar tal afirmação, ilustramos com o artigo publicado na revista Educação Physica de 1937, intitulado "Um decálogo para a Longevidade" que relata dez atitudes que propiciariam alcançar a
} 
Assim, a partir dessas perspectivas, buscamos descobrir como se configurou o campo da prática de atividade física para o idoso no Brasil.

Tivemos como objetivos específicos: (i) apontar intelectuais da época com destacada atuação dentro da construção do campo do idoso/atividade física; (ii) identificar instituições que contribuíram para difundir a prática das atividades físicas para idosos; (iii) identificar que campos teriam sido fundamentais para colaborar na construção de um novo habitus por parte dos idosos no tocante às atividades físicas; e (iv) investigar em que período as práticas físicas especificamente para idosos começaram a acontecer de forma institucional.

\section{Método}

Metodologicamente, optamos por utilizar entrevistas não estruturadas do tipo guiada. Segundo Gay (1976), ao elaboramos um roteiro para as entrevistas, buscamos as mesmas ou semelhantes informações dos entrevistados. Essa ferramenta permite ao entrevistador ajustar a sequencia e o vocabulário das questões em função do respondente. Esse roteiro cobre as áreas de interesse da entrevista, e é dada ao entrevistador a liberdade de explorar, aprofundar, elucidar o assunto objeto do estudo.

As entrevistas tiveram roteiros que respeitavam as peculiaridades do entrevistado mediante sua relação com o objeto do estudo. Apesar de distintos, os roteiros mantinham entre si itens correlatos, como a importância do SESC, instituição apontada como precursora das atividades para idosos; a opinião dos entrevistados sobre o período em que idosos teriam começado a prática de atividades físicas; mais informações sobre os nomes que iriam ou já teriam sido entrevistados e com isso ratificando ou retificando

longevidade". Destacamos a sugestão inusitada número V: "Durma seis horas pelo menos e nunca mais de sete e meia com o quarto às escuras e a janela aberta". 
dados; a visão da sociedade sobre os idosos na época em que o entrevistado estava atuante; e os motivos que levaram os entrevistados a realizarem suas atividades com os idosos.

$\mathrm{Na}$ análise, interpretação e discussão, empregamos a teoria do campo de Pierre Bourdieu, a qual carrega explicações/definições que possibilitam compreender a dinâmica social intra e extracampo.

Assim, o surgimento de um campo é reflexo de diversos fatores, os quais convergem para uma determinada situação que dinamiza um novo mecanismo particular.

Cada vez que se estuda um campo novo, descobrem-se propriedades específicas próprias a um campo particular, e ao mesmo tempo avançase no conhecimento dos mecanismos universais dos campos que se especificam em função de variáveis secundárias (BOURDIEU, 1983, p. 89).

Dentro do seu conceito de campo, o autor afirma que invariavelmente existe uma relação entre o microcosmo e o macrocosmo, mas o primeiro dispõe de certa autonomia, que varia de campo para campo. Essa relativa autonomia é que torna as leis internas dos campos distantes do macrocosmo.

Dessas tensões, podemos identificar como os agentes sociais manifestam-se, disputando, concordando, discutindo as normas que regem o interior dos campos. Esse processo interno reflete-se em todos os campos, dando-lhes a similitude que possibilita as analogias e a identificação de sua construção. A partir dessa compreensão, buscamos analogias entre o precursor campo internacional e o novo campo nacional do idoso, que foi decisivo para o surgimento das atividades físicas para esse público. 


\section{Os entrevistados}

Baseado nos fatos e acontecimentos que mantinham relação com o objeto deste estudo, elencamos alguns nomes que foram fundamentais dentro do processo de construção do campo dos idosos e ou da atividade física no Brasil, apresentados a seguir:

Antônio Boaventura da Silva (BOAVENTURA), ex-professor da USP, é apontado por Cunha Jr e Melo (1999) como precursor no campo interventivo com atividades para idosos no Clube Sírio em São Paulo no final dos anos de 1960 e posteriormente, na própria USP, com professores catedráticos no início dos anos de 1970. Também atuou na produção do conhecimento escrevendo sobre idosos e fazendo parte do corpo docente do primeiro curso de pós-graduação stricto-sensu do Brasil e da América Latina.

Fernando Telles Ribeiro (RIBEIRO), professor de educação física, traduziu e dialogou na produção do artigo que preconizava, na década de 1960, a prática de atividades físicas específicas para idosos (1968).

Marcelo Salgado (SALGADO), assistente social, com especialização em gerontologia, foi fundamental dentro do SESC, importante instituição no campo da intervenção para idosos no Brasil, além de ter participado significativamente na construção de uma legislação para o idoso. Seu nome aparece em documentos oficiais e também no artigo de Melo e Cunha Jr (1999).

Maurício Leal Rocha (ROCHA), ex-professor da Universidade Federal do Rio de Janeiro, desenvolveu trabalhos de pesquisa com idosos. Orientou a primeira dissertação sobre idosos no Brasil na área da Educação Física em $1986^{3}$ e realizou estudos

\footnotetext{
${ }^{3}$ SOBRAL, S. B.. Proposta de ação pedagógica e prática de Educação Física centrada na pessoa idosa, com ênfase nas necessidades humanas básicas. 1986. Dissertação (Mestrado) - Universidade Federal do Rio de Janeiro, Rio de Janeiro.
} 
na Suécia, na área da fisiologia do exercício. Em suas investigações sobre a saúde do povo brasileiro, também estudou os idosos em 1956, período em que as preocupações ligadas às atividades físicas para idosos ainda não figuravam no cenário acadêmico brasileiro.

As entrevistas foram autorizadas através do Termo Livre e Esclarecido de Consentimento, em consonância com as Normas e Diretrizes Regulamentadoras da Pesquisa Envolvendo Seres Humanos - Res. CNS 196/96 (BRASIL, 1996). Posteriormente, foram transcritas e enviadas aos autores que fizeram a revisão de suas falas.

\section{Bourdieu, o idoso, a atividade física}

Pierre Bourdieu e sua teoria do campo tornaram-se uma lente de aumento que possibilitou avaliar os dados obtidos e compreender melhor onde estes se encaixavam dentro da trama histórica que buscamos apresentar. As ideias básicas de sua teoria foram aqui mencionadas para ajudar no alinhamento do leitor com a forma pela qual os autores imaginaram que os eventos relacionados entre idosos e atividade física começaram a trilhar juntos o mesmo caminho.

A hipótese embasada/discutida pelo autor consiste em supor que, entre esses dois polos distantes - entre os quais se supõe que a ligação possa se fazer -, existe um universo intermediário, no qual estão inseridos os agentes e as instituições que produzem, reproduzem ou difundem o conhecimento do campo.

Os campos se apresentam "como espaços estruturados de posições, cujas propriedades dependem das posições nestes espaços, podendo ser analisadas independentemente das características de seus ocupantes” (BOURDIEU, 1983, p. 89). 
O estudo dos campos com sua autonomia permite acreditar em uma teoria geral que faz analogias entre as pertinências desses campos. Por isso, usar o que se aprende em um determinado campo pode servir para inferir e ou interpretar outros campos $^{4}$.

\section{O Campo e sua Dinâmica Interna}

A estrutura de um campo é um estado da relação de força entre os agentes ou instituições engajadas na luta da distribuição do capital específico ${ }^{5}$, o qual, acumulado no curso das lutas anteriores, orienta as estratégias posteriores.

Devemos atentar para o fato de que esse capital específico vale para certo campo e para os limites deste; contudo, quando se tenta levá-lo para outro campo, sua transformação se dá sob certas condições. Por isso, quando o conhecimento sobre a atividade física comumente aceita foi trazido para os idosos e sua intervenção teve início, uma transformação nos conceitos e percepções sobre a influência benéfica desta no envelhecimento despertou certo grau de desconfiança, sendo necessário tempo para sua completa aceitação.

Cabe ressaltar que os interesses e objetivos decididos dentro de um campo podem influenciar outros campos. Bourdieu (2004a) cita que muito do que se pesquisa na ciência é, na realidade, um conjunto de proposições impostas pelos agentes que detêm o poder. Muitas vezes, o conjunto das questões que importam para os pesquisadores reflete interesses daqueles que, durante o jogo, influenciam os rumos das pesquisas para as áreas que a eles momentaneamente mais importam. Dessa forma,

\footnotetext{
${ }^{4}$ Cada vez que se estuda um campo novo, descobrem-se propriedades específicas próprias a um campo particular, e ao mesmo tempo avança-se no conhecimento dos mecanismos universais dos campos que se especificam em função de variáveis secundárias. (BOURDIEU, 1983).

${ }^{5}$ Tipo de capital que se relaciona ao prestígio pessoal que repousa quase exclusivamente no reconhecimento dos pares.
} 
médicos, gerontólogos, professores de educação física, assistentes sociais, políticos que tivessem interesse e influência sobre o campo da saúde, político ou econômico, por exemplo, acabariam por forjar as características do crescente novo campo do idoso e suas vertentes como a atividade física que surgiria como um apêndice deste último.

Werneck (2000) explica que, com o espantoso desenvolvimento dos meios de comunicação de massa, a globalização atinge múltiplas dimensões do nosso cotidiano, dentre elas a do lazer, o que em muitos casos engloba as atividades físicas. Dessa forma, buscar um envelhecimento ativo, além de servir para ocupar um tempo em que as imposições do trabalho podem não exercer maiores pressões, atende uma demanda instituída pelo sistema, que reverbera a busca pela saúde.

Podemos perceber o binômio influência/interesse quando geriatras e gerontólogos desenvolvem o saber, que acaba por definir formas de conduta apropriadas pelo Estado, o qual define uma política de envelhecimento condizente com seus próprios interesses, criando assim uma espécie de pastoral do envelhecimento ativo.

Apesar de, sob o ponto de vista dos dominantes, ser aparentemente fácil alterar os rumos de um determinado campo e manipular as tensões e as lutas internas, trata-se de uma tarefa de extrema dificuldade. As oportunidades de um agente singular submeter aos seus desejos as forças do campo são proporcionais à sua força sobre o campo, isto é, à sua posição na estrutura da distribuição do capital. Ou seja: a força dentro do campo é diretamente proporcional à possibilidade de manipulá-lo. Contudo, cabe ressaltar que, quanto mais novo é um campo, menor deverá ser o seu poder de refração ${ }^{6}$. Campos bem estruturados, com suas peculiaridades já bem estudadas e reconhecidas, tendem a sofrer cada vez menos influências intra ou extracampo.

${ }^{6}$ Capacidade do um campo de resistir às influências do macrocosmos. Quanto mais autônomo for um campo, menos ele é suscetível às influências, ou seja, maior o seu poder de refração (BOURDIEU, 1983). 
Um indivíduo que nasce em determinado campo vale-se dos conhecimentos oriundos dele para o controle das leis não escritas, as quais se inscrevem na realidade em estado de tendências. Aprender a ler nas entrelinhas é uma arte de sobrevivência tanto para os de dentro, como para os de fora, que buscam alcançar uma posição em um novo campo. Essa espécie de ciência gera um sentido do jogo inerente ao nativo do campo. Por isso, ao adentrarmos em um campo que não é o nosso, a competição interna gera aos recém-chegados uma necessidade de se adequarem e aceitarem as leis impostas pelos dominantes, já que uma tentativa intermitente, desarticulada e acima de tudo pretensiosamente revolucionária, poderá gerar uma exclusão do campo (BOURDIEU, 1983).

O fato de um agente social relacionar-se com outros cria tensões intracampo que se refletem na própria dinâmica e nos rumos do grupo. Essas relações, que são invisíveis, são sentidas de forma integral pelos membros, os quais interagem ou sofrem influências delas, tornando-se incompreensíveis para os de fora ou pouco compreensíveis para os recém-chegados. Muitos dos conhecimentos sobre os idosos foram obtidos a partir de estudos ou observações de outros países. Tentar aplicar o que se aprendeu em outro campo a um campo já existente ou novo requer primeiramente capital específico, ou seja, conhecimento sobre o campo que se quer influenciar/transformar, assim como o seu poder de refração. No caso do campo do idoso brasileiro, ainda novo e com baixo poder de refração, as influências foram aos poucos assimiladas e, com o passar dos anos, tornaram-se a ortodoxia do campo.

Por isso, algumas mudanças ou quebra de paradigmas só se fazem sentir anos após o início de sua transformação. As incompreensões por parte dos de fora, que não se dão conta do processo evolutivo (ou mesmo involutivo), conduzem os demais ao 
ostracismo, segregando os que aderem às mudanças rapidamente, ou por fazerem parte do campo ou por serem recém-chegados. Idosos que tentassem realizar atividades físicas em um momento histórico em que essa conduta não representava um habitus, certamente seriam segregados, ou no mínimo tidos como diferentes.

Apesar do poder de refração de cada campo, ao longo do tempo, as mudanças em nível macro acabam por serem absorvidas em nível micro, conduzindo os campos a caminhar rumo aos desígnios históricos da sociedade. Podemos apontar que o campo econômico, em especial, gera esse tipo de condução. Em nível macro, uma decisão política como os anos necessários para a aposentadoria acaba por ter reflexo em nível micro na vida de cada cidadão.

\section{Análise e discussão dos dados \\ O início da construção de um Paradigma: Rocha, Ribeiro e Boaventura: os precursores}

No intuito de investigar os primórdios das reflexões/teorias e práticas sobre as atividades físicas para idosos, encontramos em Rocha (2004) fontes que apontavam estudos com idosos em 1956. Assim, buscamos uma entrevista com o Professor Maurício Leal Rocha,

Segundo Furtado e Novaes (2004), Rocha teria sido um dos protagonistas da implantação da medicina esportiva no Brasil. Dentre as diversas ações desenvolvidas por Rocha, destacamos o Projeto Brasil, que foi o pioneiro na avaliação da saúde dos parâmetros indicadores das valências físicas da população brasileira e dos pressupostos para ações que gerassem a melhoria da qualidade de vida do povo brasileiro. 
Em entrevista, o médico, professor e pesquisador Maurício Leal Rocha, excoordenador do Laboratório de Fisiologia (Labofise), da Universidade Federal do Rio de Janeiro (UFRJ), descreveu suas reflexões e contribuições acerca do processo de envelhecimento e da atividade física. Revelou que, em meados dos anos de 1950, ao voltar da Suécia após fazer uma especialização, começou a desenvolver trabalhos com idosos, com vistas a apontar os seus limites durante a atividade física e, com isso, promover uma adaptação condizente com a situação etária do indivíduo.

Seu livro intitulado “Aspectos Diversos da Medicina do Exercício”, de 2004, contém gráficos que analisam o volume cardíaco e a atividade física de diversos indivíduos, evidenciando resultados de pesquisa realizada com homens destreinados e idosos. Ao longo de sua permanência no Labofise, Rocha desenvolveu diversas pesquisas com idosos, priorizando variáveis como fadiga, supertreinamento, hipertensão, diabetes, dentre outras, por meio de análises feitas à luz de experimentos que incluíam testes físicos e laboratoriais.

Sob a coordenação de Rocha, surge nos anos de 1970 o Projeto Brasil, o qual figurava como um dos programas de pesquisa desenvolvidos pelo Plano Nacional de Educação Física e Desporto (PNEFD) e tinha como preocupação desvelar a condição do homem brasileiro no tocante à aptidão física, promovendo estudos de ambos os sexos e diversas faixas etárias.

A percepção de que muitos idosos trabalhavam de forma "braçal" - ou seja, submetiam-se a sessões de atividades físicas laborais diárias para a sobrevivência, valendo-se de sua condição física - levou Rocha a averiguar os efeitos dessa prática, realizando testes ergométricos e de antropometria, assim como exames laboratoriais. 
[...] Encontrei muitos idosos nos locais onde visitei, no Projeto Brasil. Quando fui nesses locais para pesquisar sobre a condição física do homem brasileiro, encontrei muitos idosos ainda trabalhando para sobreviver [...] (ROCHA).

Indagado sobre a originalidade de sua pesquisa no cenário brasileiro da época, Rocha assim nos respondeu:

[...] Sim, pois trabalhou muito a questão da aptidão física, motora, qualidade de vida; tudo isso ligado aos idosos, que na época não tinham nenhum tipo de trabalho visando estas valências [...] (ROCHA).

Entretanto, conforme salientou o entrevistado, estudos nessa área já existiam na Suécia, onde realizou um curso em meados dos anos de 1950, Percebe-se, portanto, a interação em nível internacional e nacional, evidenciada pelo fato de pesquisas e avanços em outros campos terem servido de exemplo para as iniciativas em nosso país. Tal informação sobre as atividades de vanguarda com idosos nos países escandinavos já tinha sido ratificada em Holloszy (1993).

Entretanto, as pesquisas iniciadas nos anos de 1960 não repercutiram de forma imediata, alterando a visão sobre idosos e atividades físicas e as práticas sociais da época, cuja popularização se deu anos mais tarde, na década de 1970/80, segundo o entrevistado.

Como vemos, até então não existiam trabalhos interventivos sistematizados com idosos, e pesquisas nessa área começavam a surgir oriundas do campo da saúde, em que a profilaxia era a tônica.

O Serviço Social do Comércio de São Paulo - SESC realizou um estudo de resgate da história dos idosos intitulado "Trabalho Social com Idosos". Em 1962, o SESC enviou aos Estados Unidos da América um grupo de técnicos para observar os 
trabalhos desenvolvidos em centros sociais para idosos, os Golden $\operatorname{Age}^{7}$, que se propagavam por diversas cidades americanas. Tais centros surgiram no intuito de suprir as deficiências dos idosos no atendimento às necessidades decorrentes das transformações sociais que ocorriam naquela sociedade. Após o retorno dos técnicos, foi criado um programa de atendimento específico para pessoas aposentadas, que teve seu início no centro social "Mário França de Azevedo", situado na Rua do Carmo, 147, no centro da cidade de São Paulo.

Constatamos em nossas entrevistas e pesquisas que o SESC surge como uma das instituições pioneiras na promoção de atividades com idosos. Além do SESC, o gerontólogo Marcelo Salgado é frequentemente citado como um dos precursores dos estudos acerca das atividades físicas com idosos no Brasil.

Nesse contexto, faz-se necessário destacar um dos primeiros artigos a disseminar as atividades físicas para os já idosos, visando à melhora do condicionamento físico. A partir de Telles e Mourão (2006), localizamos o seu autor que aparece como um agente social que merece destaque.

Em um periódico denominado "Boletim Técnico Informativo do Ministério da Educação e Cultura" encontramos o artigo do professor de educação física Fernando Telles Ribeiro, que em 1968 apresentou o artigo "Exercício Físico e Longevidade". baseado em informações obtidas do Comitê Olímpico Búlgaro. Na introdução, o autor alega que as atividades físicas para idosos constituem um novo campo da educação física, dando indícios de que ainda engatinhávamos nas descobertas no campo gerontológico.

\footnotetext{
${ }^{7}$ Centros de convivência que foram criados nos EUA e tiverem significativa disseminação em todo o país, com forte ligação com o lazer em um amplo sentido cultural, integrado nos parâmetros de uma educação permanente do ser humano (SESC, 1999).
} 
[...] A longevidade humana observada através dos efeitos do condicionamento físico é um novo campo de experimentação da educação física. Não somente a geriatria tem se aproveitado dos resultados como também a fisiologia aplicada ao treinamento [...] (RIBEIRO, 1968, p. 37).

$\mathrm{O}$ artigo relata resultados de pesquisa realizada com adultos de 55 a 60 anos, os quais foram sistematicamente treinados com exercícios físicos adequados, que reconhecidamente provocariam hipertrofia nos jovens.

Ao analisarmos o artigo com os conhecimentos atuais, levando-se em consideração os 46 anos que já se passaram, percebermos que o autor define o resultado como "surpreendente". Porém, os experimentos realizados basearam-se no pressuposto de que, como a involução e atrofia são processos irreversíveis da natureza e se o fenômeno de involução é inevitável, exercícios físicos não iriam surtir hipertrofia muscular ou mesmo sensível dilatação do coração em indivíduos de 50 anos em diante, como normalmente ocorre em indivíduos jovens.

Interessa-nos nesse estudo perceber como pensavam as pessoas que no Brasil deram início às atividades voltadas para idosos ou ainda tentar descobrir o que os intelectuais da época pensavam sobre tais atividades. A conclusão do trabalho foi de que houve hipertrofia nos músculos submetidos à ativação funcional e seus índices de força aumentaram consideravelmente.

Esses estudos, entretanto, ainda são insuficientes [...] mas de grande importância é o fato em si mesmo: indivíduos de idade quando submetidos à atividade funcional com exercícios físicos, ao invés da esperada atrofia apresentam, ao contrário, hipertrofia na musculatura [...] (RIBEIRO, 1969, p. 38). 
Com a intenção de nos aproximarmos ainda mais das ideias que circulavam no Brasil sobre as atividades físicas para idosos, marcamos uma entrevista com Fernando Telles Ribeiro em sua residência no Rio de Janeiro.

Ribeiro, além de professor de educação física, é engenheiro. Participou de campeonatos Mundiais Masters, conseguindo resultados expressivos. Como atleta, sagrou-se campeão carioca, brasileiro e sul americano de saltos ornamentais, além de ter participado de duas edições dos Jogos Olímpicos (1956 em Helsinque e 1960 em Roma).

Em entrevista, Ribeiro mostra preocupação com a situação da educação física de sua época, que ainda procurava seu espaço, não estando legitimada, sendo apenas uma formadora de professores de ginástica e também para atuarem em escolas.

Indagado sobre o que o levou a escrever o artigo, confessou não ser seu autor, revelando ter sido o tradutor do artigo do Comitê Olímpico Búlgaro, por achar que aquilo deveria ser divulgado. Segundo Ribeiro:

[...] esse artigo foi do comitê Olímpico Búlgaro que por acaso a revista estava em cima da mesa da federação (atual Federação Aquática do Estado Rio de Janeiro)... Aí eu pensei, esse negócio é importante, precisa ser divulgado [. ] (RIBEIRO).

Devido ao pouco material disponível sobre o surgimento das atividades físicas para idosos no Brasil, o artigo tornou-se para nós um marco dentro da produção acadêmica, por ser o precursor em oferecer resultados com exercícios físicos realizados com idosos. Até então somente encontrávamos estudos em que a busca pela longevidade pregava atividades físicas para os ainda jovens, não recomendando qualquer tipo de atividade física para os já em idade avançada. É importante mencionar que Rocha realizou testes diferentes dos relatados no referido artigo, e também não realizou atividades físicas de cunho interventivo com idosos. 
Nas declarações de Ribeiro, percebemos que, no período em que o artigo foi traduzido, a prática de atividades físicas não era apropriada para os idosos, os mesmos quais eram vistos como indivíduos que deveriam permanecer em casa, sem exercitarse. Ainda segundo o entrevistado, não existia nenhuma instituição que realizasse atividades físicas com idosos, embora fosse do seu conhecimento que o SESC teria sido pioneiro nessa prática, possivelmente, segundo ele, alguns anos depois da publicação do seu artigo.

Ribeiro comenta que Maria Lenk e Gastão Figueiredo ${ }^{8}$ foram pessoas que continuavam a praticar atividades físicas, mesmo depois de terem atingido uma idade que não mais se julgava apropriada para a época. Tais atitudes, segundo o entrevistado, chamavam muita atenção:

[...] tinha uns que agente achava assim fora do comum... a Maria Lenk sempre praticou, mas era um caso a parte, ela era do ambiente da educação física foi professora da Escola de Educação Física, era um exemplo, então havia um ou outro que despontava assim como o João Gonçalves...o Gastão ainda nadava depois de uma certa idade , mas não era o normal [...] (RIBEIRO).

Quando perguntado sobre o motivo que teria chamado sua atenção sobre a relevância do artigo, a resposta apontou para a preocupação com os efeitos do tempo sobre o indivíduo, pois já se começavam a perceber que o exercício físico atenuava os efeitos do tempo. Assim respondeu nosso entrevistado: "Foi com a saúde mesmo do povo de um modo geral, eu não fiz só para o esporte, começava-se a perceber que a vida sedentária era nociva” (RIBEIRO).

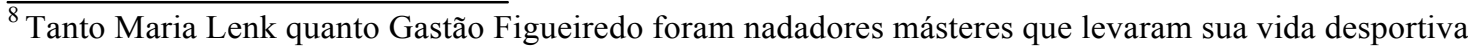
acima dos 90 anos, batendo recordes dentro da faixa etária em que competiam.
} 
Como podemos perceber, mesmo que embrionariamente, os intelectuais da época começavam a se preocupar com a questão da atividade física para os idosos.

Na época em que traduziu o artigo, Ribeiro estava com aproximadamente 29 anos de idade, chegando ao final de sua carreira esportiva. Talvez a proximidade do término de suas atividades como atleta de ponta o tenha levado a preocupar-se, mesmo que inconscientemente, com tal estudo.

A vida esportiva de Fernando Telles Ribeiro foi cheia de sucessos. Ele sagrou-se campeão em diversas competições em âmbito internacional, o que sugere que, devido à afinidade que tinha com as atividades físicas, sua permanência nessa área seria algo com grandes chances de acontecer.

Porém, percebemos que dois fatores fizeram com que Fernando voltasse a competir, mesmo já sendo idoso. O primeiro seria a perda da vergonha em praticar atividades físicas com uma idade mais avançada:

[...] quando eu ia às vezes saltar as pessoas ficavam olhando e perguntando: "O senhor vai saltar?!" Isso deixava a gente meio deslocado; hoje, não; as pessoas olham com naturalidade e dizem: "Que legal! O senhor vai saltar? [...] (RIBEIRO).

Fica claro que tais mudanças de atitude em relação à prática de atividades físicas por idosos contribuíram para que houvesse uma maior disseminação da ideia, o que somente pode ocorrer graças a transformações sociais no tocante a uma nova e renovada visão sobre o idoso dentro da sociedade. A aceitação social é um forte catalisador para deflagrar a inercial tendência dos já idosos em não praticarem atividades físicas em virtude dos entraves impostos pelo sistema e de limitações ligadas à saúde ou à ausência dela. 
$\mathrm{O}$ segundo fator que teria levado Ribeiro a retornar as atividades seria o incentivo que as competições de másteres oferecem. Se não fossem as competições, possivelmente ele não retornaria. Contudo, com os avanços nos sistemas de treinamento, ele consegue manter-se realizando saltos de relativo grau de dificuldade.

Ribeiro ressalta que ter a oportunidade de voltar a competir sentindo as mesmas emoções de quando era jovem são muito compensadoras.

[...] Quando participo de competição hoje, sinto a mesma coisa de quando era mais jovem, você fica nervoso do mesmo jeito, você leva a sério o treinamento do mesmo jeito, não quer perder, o negócio é meio paranoico, mas é divertido, saudável. [...] Agora, a motivação é muito grande, eu, por exemplo, se não fosse competição, eu não praticava. Te garanto. Só voltei a saltar sério, bonitinho, porque havia competição [...] (RIBEIRO).

Acreditamos que até aqui as pesquisas realizadas nos anos de 1960 foram propedêuticas em relação as atividades físicas propriamente ditas. Com o passar dos anos os conhecimentos produzidos nesse período iriam se propagar para embasar ou mesmo estimular que outros intelectuais começassem a pensar em uma intervenção.

\section{Em busca da Intervenção}

No estudo de Cunha Jr. e Melo (1999), Pedro Barros Silva aponta a Associação Cristã dos Moços (ACM) e o Professor Antônio Boaventura como aqueles que ofereciam atividades físicas para pessoas mais velhas, embora não se configurassem como democráticas, ou seja, programas de fácil acesso para todos.

Na ACM, obtivemos informações, ao entrevistar Boaventura e Rocha, que tais atividades não englobavam idosos, que recaíam nas atividades oferecidas para adultos e pessoas maduras. 
Dessa forma, viabilizamos uma entrevista com o Professor Antônio Boaventura da Silva, em sua residência, na cidade de São Paulo. Boaventura nos conta que teria iniciado as práticas de atividades físicas para idosos no Esporte Clube Sírio, em São Paulo, no final dos anos de 1960, onde ministrava atividades para pessoas maduras e, posteriormente, na Universidade de São Paulo (USP), para os catedráticos de outros cursos. Ele revelou ter criado esses grupos no Sírio e na USP no intuito de demonstrar a importância do professor de educação física, além de salientar a atividade física como importante vetor de promoção da qualidade de vida. Seus alunos eram pessoas na faixa etária entre 50 e 65.

[...] De modo que começamos em uma época principiante, ninguém acreditava na educação Física. A gente não ia em uma igreja ou reunião social com uniforme de ginástica, porque no fundo a sociedade estranhava e associava o professor de Educação Física a um ignorante ou não suficientemente desenvolvido a para a atividade educacional [...] (BOAVENTURA).

As intervenções de Boaventura destinavam-se aos sócios do clube Sírio e, na USP, somente aos professores. Essas iniciativas representam um avanço rumo à democratização das atividades físicas, pois Boaventura já acreditava que os mais velhos deveriam manter-se em movimento. Cabe ressaltar que não era uma atividade aberta, somente alguns poucos indivíduos poderiam participar das aulas.

Por outro lado, verifica-se que mais uma vez o campo internacional influenciou na construção de ideias sobre o campo da educação física como prática de atividades físicas em geral. Boaventura narra que esteve na Suécia e isso contribuiu para uma maior compreensão de sua prática profissional, evidenciando a contribuição do campo internacional para as práticas e as representações no Brasil. 
[...] Quando eu vim da Suécia, com os horizontes alargados para a Educação Física, eu aprendi a parte sueca. Mas havia estado nos Estados Unidos, onde fiz um ano de pós- graduação, em 1945, e lá aprendi mais do que calistenia, pois era a atividade deles. [...] E logo em seguida, convidamos um professor sueco para vir ao Brasil [...] (BOAVENTURA).

Quando perguntado sobre as atividades ministradas, Boaventura revelou sua preocupação em oferecer aos alunos atividades que se aproximassem dos movimentos naturais, as quais, segundo ele, eram mais prazerosas.

[...] Em 1951 também veio um sueco chamado Scott Johnson e depois em 1952 o Professor Listello, que além do handebol também ensinava a ginástica natural [...] Então, eu pude dar a eles, atividades o mais próximo do natural, principalmente exercícios dois a dois, três a três, quatro a quatro e às vezes cinco a cinco. Atividades espontâneas, que costumamos fazer normalmente em nossa vida e não somente levantar braços e membros [...] Sempre que possível dinamicamente, em movimento. Eu nunca pegava o indivíduo senão para se movimentar e fazer atividade física. Eu pedia sempre para saltitar naturalmente, eu fazia eles repetirem, correr ou saltitar descontraído. E sempre ligar o fim de um exercício ao início do próximo. Você não faz um exercício e sim uma série de exercícios [...] (BOAVENTURA).

As atividades físicas para idosos no Brasil sofreram uma forte influência dos preceitos do campo da saúde. Rocha, Ribeiro e Boaventura demarcam bem essa tendência. Embora o conhecimento ainda não fosse disseminado e/ou não propiciasse iniciativas mais próximas das que vemos hoje, todos os intelectuais da época produziram conhecimento transformador. Acrescenta-se a essa questão o desconhecimento sobre o avançar da transição demográfica, que ainda não era percebida pelos atores sociais, realçando ainda mais as atitudes de vanguarda desses professores. Contudo, o tempo relativamente recente entre se aposentar e morrer começa a ser preenchido lentamente para ainda poucos idosos. 
Bourdieu (2004a) explica que todo campo é um campo de forças e um campo de lutas em que os atores sociais, para conservar ou transformar a situação vigente, utilizamse de seus instrumentos para tornar o jogo mais vantajoso para si. Nesse contexto, observa-se a atenção de Rocha sobre a saúde do brasileiro, o qual, mesmo idoso, ainda trabalhava para sobreviver. A luta pela divulgação de uma profissão e seus preceitos, ressaltada por Boaventura, assim como a preocupação de Ribeiro em divulgar algo que considerava novo e importante, revelam a tentativa de controle/legitimação do campo através dos instrumentos de que eles dispunham: o conhecimento.

Todas essas ações podem ser compreendidas na perspectiva do capital específico. Podemos dizer que elas foram deflagradoras de novas possibilidades, e, aliadas a outras tensões, como as oriundas do campo internacional, as transformações nos campos político, econômico e da saúde favoreceram um novo olhar frente às intervenções com os idosos.

\section{O SESC, Marcelo Salgado e o Trabalho Social com Idosos}

Em 1946, é criado o Serviço Social do Comércio (SESC) pelo decreto lei $\mathrm{n}^{\mathrm{o}}$ 9853/46, ficando a Confederação Nacional do Comércio encarregada de criar, organizar e administrar tal entidade (BRASIL, 1946). O SESC foi inspirado nos princípios da Carta da Paz, nascida da Conferência de Teresópolis em 1945, que significava uma promessa de justiça social que seguia uma filosofia de implantação de serviços sociais custeados pelas classes patronais (SESC, 1999).

O SESC atuou em áreas onde o Instituto de Aposentadoria e Pensões dos Comerciários (IAPC) mostrava-se inexistente ou omisso. Seus recursos vinham de 
contribuições exclusivas dos empregadores, cabendo ao Ministério do Trabalho, Indústria e Comércio a aprovação do regulamento e a fiscalização das atribuições da entidade.

O SESC teve seu trabalho com idosos iniciado em 1963. Durante nossa pesquisa, todos os entrevistados e todas as fontes bibliográficas encontradas apontam o SESC como a instituição precursora em oferecer de forma ampla atividades destinadas exclusivamente para os já idosos.

Nesse sentido, o artigo de Cunha Jr. e Melo (1999) traz evidências de que as atividades para idosos surgiram no SESC nos anos de 1960, onde foi implantado um programa de atividades físicas para pessoas de 40 a 90 anos, que praticavam diferentes esportes adaptados, tais como voleibol, basquetebol, com a predominância de mulheres. Seu relato reconstruiu como tal passagem aconteceu, tendo início mais precisamente no SESC da capital de São Paulo. Segundo ele, as atividades foram oferecidas aos idosos que frequentavam um restaurante do SESC na Rua do Carmo, que, após as refeições, ficavam parados sem qualquer ocupação.

Foi o orientador social Carlos Malestra que começou a reunir os idosos e lhes ofereceu atividades de lazer, jogo de baralho, dominó, abriu-lhes a biblioteca e começou a fazer reuniões. Com essa iniciativa, foram criados núcleos em outros SESC e grupos que não pertenciam a essa entidade, mas trabalhavam com idosos, foram convidados e integrados em uma única forma de trabalho. Barros cita Renato Requixa e posteriormente Marcelo Salgado como dois professores que atuaram nesta unificação. Ainda no relato, Barros comenta que bolsas teriam sido dadas para professores investigarem o que acontecia na França e EUA. Nesse período, a França passava por transformações significativas dentro do contexto social voltado para a terceira idade, tanto que se tornou a pioneira na criação da primeira Universidade da Terceira Idade, em 1973. 
[...] o SESC trabalhou... especificamente com o idoso dentro de suas unidades[...]o SESC começou a unificar esses grupos que trabalhavam [...] mesmo que não fossem do SESC...junto com o SESC...e aí surgiu o trabalho do Professor Renato Requixa e futuramente ...seguido pelo Marcelo Salgado...quer dizer começou a turma a ir para a França ver o que existia na França...deram bolsas de estudos e ...foi se integrando ao trabalho de idoso que foi crescendo e crescendo dos quais até a Universidade da Terceira Idade foi fundada em Campinas [...] (CUNHA JR.; MELO, 1999, p. 3).

Barros confirma o pioneirismo institucional do SESC na criação de atividades para idosos, porém aponta duas $^{9}$ outras entidades que realizavam atividades em caráter isolado e de forma elitista. O primeiro citado seria a ACM (Associação Cristã de Moços), que atuava com pessoas maduras, com ginástica de conservação, contudo havia pagamento de mensalidade, além de ter que ser associado. $\mathrm{O}$ outro trabalho foi realizado na Escola de Educação Física da USP, que tinha um núcleo que trabalhava com catedráticos através do Professor Boaventura, que também realizava trabalhos semelhantes no Tênis Clube ${ }^{10}$ em São Paulo.

Barros relatou a Cunha Jr e Melo (1999) que, no início, não tinha sido fácil. Cartas eram enviadas aos idosos aposentados do IAPC, contudo não eram obtidas respostas,; assim, poucos se dirigiam ao local proposto para início das atividades. Então, o orientador social Carlos Malestra passou a fazer os convites aos idosos pessoalmente nas agências do IAPC. Tal atitude alavancou as atividades e, em 23 de setembro 1963, elas foram iniciadas.

\footnotetext{
${ }^{9}$ As duas citações já foram aqui apresentadas e esclarecidas.

${ }^{10}$ Cabe ressaltar que Boaventura na verdade não trabalhou no Tênis Clube com idosos e sim no Clube Sírio. No primeiro, trabalhou com jovens entre 12 e 15 anos.
} 
No intuito de aprofundarmos os estudos sobre como foi o início das atividades no SESC, buscamos uma das fontes apontadas no artigo de Cunha Jr e Melo (1999) gerontólogo Marcelo Antônio Salgado -, já que Pedro Barros Silva é falecido.

Salgado acumulou uma experiência de mais de 30 anos como diretor do Programa Trabalho Social com Idosos do SESC de São Paulo, que se tornou uma referência no trabalho com a terceira idade, reconhecido em todo o mundo. Em seu extenso currículo, Salgado acumula diversos títulos e cargos, sempre relacionados à gerontologia, como: expert do Centro Internacional de Gerontologia Social (França), Conselheiro da Federal Internacional de Idosos (órgão consultivo da ONU), assessor do Governo de Portugal para a organização de projetos com idosos, entre vários outros.

Salgado nos relata como se deu o início das atividades no SESC e menciona que não existiam atividades físicas:

[...] o SESC começou o trabalho em 63... [...] Mas esse profissional (Calos Malestra) tinha visto alguma experiência com velhos nos Estados Unidos e tentava implantar isso numa unidade do SESC - que foi exatamente o trabalho que é o relatado como o de mil, novecentos e sessenta e três, mas esse trabalho de sessenta e três, que foi relatado aqui, era apenas um embrião... Ele conseguiu, com muita dificuldade, como técnico, que criassem uma pequena operação, fazendo a divulgação nas filas de pagamento dos aposentados do IAPC, que era o Instituto de Previdência dos Comerciários antes do INPS, e reuniu alguns senhores idosos, mais alguns outros que freqüentavam o restaurante desta unidade específica do SESC onde se originou o primeiro trabalho e este profissional - que era um assistente social, foi que fez a primeira ampliação, mas o trabalho ficou naquilo: se reuniram algumas pessoas, dessa forma... e o trabalho ficou nisso. Eram doze ou quatorze senhores..[...] se reuniam numa sala numa unidade do SESC, ficavam ali orientados por um estagiário de serviço social), ficavam conversando, batendo papo, jogando dama... assim era o trabalho do SESC (SALGADO).

Bourdieu (2005) já explicava que uma das estratégias universais dos profissionais do poder simbólico consistia em pôr o senso comum ao seu próprio lado. 
Manter a autoridade também consiste em deter o conhecimento sobre o campo em que se atua. Preconizar atividades físicas para idosos era, nos anos de 1970, uma ação que deveria ultrapassar diversos obstáculos - nada mais natural dentro de um período de transição em que o volume de transformações nas mais diversas áreas começava a acontecer. Salgado assim descreve como foram as primeiras posições dos médicos quanto à prática de atividades física para idosos:

\begin{abstract}
O médico chegou pra ela, olhou e disse assim: "Dona Carmem, com esta idade, com este corpo, com estas varizes que a senhora tem na perna... a senhora é louca!" [...] A limitação, tanto dos médicos quanto dos profissionais de educação física, mas não era porque eles desconhecessem era porque eles partiam do preconceito que era... Hoje eu compreendo; na época eu me revoltei contra... Hoje eu entendo: porque eles faziam parte, eles tinham aquela cultura coletiva, era senso comum de que o velho era frágil, que o velho não tinha possibilidade, que o corpo do velho... entende?... Era isso: que era perigoso... Não pode ser perigoso, gente!... A gente faz um baile, eles dançam a noite inteira aqui, bebem feito um condenado, estão ótimos no dia seguinte né? (SALGADO).
\end{abstract}

Esse relato não teve a intenção de desabonar a conduta do referido médico, ainda mais porque não sabemos a real condição do estado da idosa que buscava atividade física naquele momento. Atualmente, o fato de ter varizes (dependendo do nível) não se caracteriza como um fator impeditivo para a prática sistemática de atividades físicas e considera-se o sedentarismo como um dos fatores que aumentam as possibilidades do surgimento delas.

$\mathrm{Na}$ verdade, chama atenção o fato de que justamente quem tem o conhecimento não recomendava a prática. Suplantar essa situação requer tempo e difusão dos novos conhecimentos. Ao perceber que atitudes como essa eram recorrentes dentro do SESC, Salgado promoveu uma reunião que começou a mudar a atitude de todos os envolvidos. 
Percebemos como os paradigmas são difíceis de serem quebrados. Um conhecimento produzido no passado, que de tão antigo torna-se senso comum, é reproduzido tanto por indivíduos com capital específico pequeno como os leigos, como também por professores de educação física e médicos, que detêm maior conhecimento.

Salgado também é autor de diversos livros sobre idosos e relata que sempre teve vontade de trabalhar com pessoas mais velhas, por isso buscou no SESC uma forma de realizar seu desejo.

O conhecimento de geriatras e gerontólogos foi fundamental para que o poder público começasse a desenvolver ações em relação aos idosos. Através do conhecimento disseminado por esses profissionais, as intervenções em diversos âmbitos da vida do idoso se tornaram mais evidentes e compreensíveis.

Salgado foi protagonista das discussões e propostas no campo do idoso no Brasil. Bourdieu (2004b) cita que o Estado, através de uma nomeação oficial, legitima quem a ele interessa, utilizando o capital específico de determinado ator social, conferindo-lhe poder para deflagrar mudanças ou a manutenção no campo que ora quer manipular.

De fato, Salgado ressalta que trabalhou junto ao governo no intuito de desenvolver propostas e ideias pertinentes a uma primeira legislação voltada ao idoso.

[...] Isso foi em setenta e cinco, setenta e seis. Eu não me considerava nenhum doutor, embora eu já desse aula em universidade, mas não era nenhum grande "expert" nisso, mas fui convidado exatamente porque tinham,eles tinham um pedido do Ministro, para as pessoas que iam compor o Ministério e elas já tinham uma referência do meu trabalho e intencionavam alguma ação nessa área. E aconteceu que, depois dessa reunião eu fui convidado, eu fui requisitado no SESC, se criou o Ministério e o Ministério tinha uma secretaria que tem até hoje, de Ação Social que cuida de políticas públicas e eu fui requisitado no SESC para trabalhar nessa secretaria, onde tive a oportunidade de criar o primeiro programa, o Primeiro Plano Nacional de Assistência ao 
idoso, que foi o embrião de todas as políticas sociais que foram passando .[...]Isso em setenta e seis......] (SALGADO).

O SESC e o governo já protagonizaram uma das preocupações sobre a construção da ideologia da velhice apontada em Haddad (1986). A autora comenta que a ideologia médica sobre a velhice fundamenta e ajuda na construção sobre a ideologia da velhice produzida pelo Estado brasileiro e que também deu subsídios à ação do SESC, o qual se utiliza igualmente dos conhecimentos desses especialistas.

Dessa forma, concordamos com Haddad quando percebemos que uma política pautada nos conhecimentos médicos foi desenvolvida para minimizar as condições desfavoráveis dos indivíduos, conquistadas ao longo de uma vida penosa e cheia de injustiças sociais. Ao final da vida, esperar que programas que inculquem na sociedade uma "pastoral do envelhecimento ativo" 11 baseado em saberes médicos, que constituem uma tábua de leis dogmaticamente impostas à sociedade, é ignorar a história de vida de muitos que, durante toda a existência, sequer pensaram em uma atividade dentro desses padrões agora estabelecidos.

Como pensar em uma pastoral do envelhecimento para indivíduos caracterizados por Magalhães (1989) como pseudoidosos que aparentam uma idade biológica que não reflete a cronológica? Indivíduos que passaram uma existência inteira sofrendo, na tentativa de uma sobrevivência digna, e que agora, ao chegarem ao final da vida, recebem indicações sobre um ativismo que, em muito pouco tempo, resultará em melhoras para o seu organismo já comprometido pelo seu estilo de vida carcomido pelo sistema.

Vivemos em uma perspectiva na qual a espera por um futuro melhor secundariza o presente. Contudo, neste presente, o destino já demonstra que as

\footnotetext{
${ }^{11}$ Conceito amplamente discutido na tese de Alves Jr. (2004)
} 
possibilidades de reversão de um quadro político-social injusto, para grande parte da população, construído durante anos de uma vida explorada, tornam-se cada vez mais utópicas.

Propor um ativismo às classes menos favorecidas é ao mesmo tempo delegar ao cidadão que se salve de uma velhice condenada à dependência e à penúria. Apesar de as condições dos idosos nos países desenvolvidos não serem justas para todos, a vida em outras faixas etárias mostra-se muita mais cheia de possibilidades, potencializando uma qualidade de vida no presente, que no futuro representará uma velhice em condições mais dignas das que vivemos em nosso país.

As classes média e alta são aquelas que mais iriam valer-se desse campo das atividades físicas que começava a surgir. Independentemente disso, e apesar disso, esse campo se constituiu. Antes, nem mesmo aqueles que tivessem condições utilizariam as atividades físicas para melhorarem sua qualidade de vida na velhice.

O SESC, apesar de caracterizar-se como uma entidade patronal, realiza até hoje atividades que deveriam ser em essência um serviço do Estado. Contudo, dentro de seus preceitos burgueses atrelados à manutenção do status quo, o trabalho social com idosos representa um marco na propagação de ações com os idosos brasileiros.

Os anos de 1970 iniciaram a construção dos direitos dos idosos em nosso país. Os desdobramentos dessas movimentações em torno dessa faixa etária acabariam por originar também preocupações com as questões ligadas ao corpo.

O campo internacional, em especial o europeu, foi fundamental para deflagrar algumas transformações em relação à política do idoso em nosso país. Salgado ressalta que assim pensou nas atividades físicas para os idosos no SESC: 
[...] Ao mesmo tempo, nesta época, eu tinha feito um estágio na Alemanha e na Alemanha já tinham, na Alemanha eu não via atividade física para velhos saudáveis, eu via mais a nível até de reabilitação, mas, enfim, para muitos, aquilo que eu assistia como uma ginástica reabilitadora, era uma coisa, preventivamente, seria ótimo para aquelas pessoas que estavam entrando naquela fase da vida e feito com muito sucesso também... Então, quando eu cheguei aqui, propus ao SESC, reuni meia dúzia de professores, muito tímidos na época e vamos fazer uma coisa - evidentemente nos cercamos de cuidado, pedimos um exame médico, uma avaliação cardiológica, uma, se possível, uma coisa para medir o esforço, muito embora, se você faz isso com cuidado, salvo se a pessoa tenha algum problema [...] (SALGADO).

O estudo das características provenientes dos campos, levando em consideração sua autonomia, permite acreditar em uma teoria geral que faz comparações entre os campos se tornarem possíveis. Por isso, usar o que se aprende em um determinado campo pode servir para inferir e/ou interpretar outros campos. (BOURDIEU, 1983). Assim fez Salgado ao interpretar o campo internacional: vislumbrou as possíveis aplicabilidades no Brasil, adequando as inovações por ele identificadas às condições em que elas poderiam ser realizadas na realidade brasileira.

Ao perguntar se ele acreditava que de fato teria começado as atividades interventivas com idosos no SESC em 1977 e ainda se, na condição de intelectual ligado aos idosos, reconhecia sua atração como protagonista nesse campo, obtivemos a seguinte resposta:

[...] Posso te garantir que a primeira experiência, pelo menos formalmente, organizada, reconhecida, foi lá [...] No SESC Consolação, na época chamava-se Carlão... [...] Carlos de Souza Nazaré [...] Eu não sei se, eventualmente, eu não posso garantir a você se já houve alguma especulação científica, entende?... algum estudo... pode até ter havido, mas também acho que não... Agora, que resulta $[\ldots]$ (SALGADO).

Destacamos a forma como Salgado acabou por participar na implantação, em todo o país, de trabalhos sociais com idosos. Ele foi convidado a ir ao Congresso 
Nacional para explicar suas ideias e ações dentro do SESC São Paulo sobre o desenvolvimento de atividades físicas praticadas por idosos.

[...] Eles não tinham visto isso. Agora, paralelamente, aconteceu uma coisa que alguém, que eu não sei, disse que eu estava sacrificando os velhos no SESC, fazendo atividade física, e aí eu fui envolvido numa CPI do Congresso Nacional e de... de pessoa indiciada para depor, eu me transformei em consultor da CPI [...] (SALGADO).

Como consultor, ele planejou os trabalhos a serem propagados em todo o país.

Nessa mesma época, Jessé Pinto Freire era Senador da República, cargo que exerceu de 1971 até 1980, ano de seu falecimento, tendo atuado também como presidente da Confederação Nacional do Comércio entre os anos de 1965 e 1980.

Salgado, que era funcionário do SESC São Paulo e já realizava trabalhos com idosos em seu estado, ao encontrar-se com Freire durante seu depoimento na CPI, solicitou-lhe que estendesse esse trabalho pelas outras unidades do SESC em todo o Brasil.

[...] No dia seguinte, dez horas da manhã, eles estavam lá. Aí ele (Freire) entrou na sala e disse assim: "Marcelinho..." - ele me chamava de Marcelinho - "vai dizer a coisa maravilhosa que você faz. Quero esse trabalho implantado em todo Brasil." Daí, quer dizer, por ordem, por decisão de Jessé Pinto Freire, a partir desse depoimento na CPI, que ele mandou implantar o trabalho em todo o Brasil, porque o SESC Nacional não executava - tanto que quando eles começaram a tentar fazer o trabalho, já tinha o trabalho implantado em diversas unidades do Nordeste, que foi orientado por mim, cedido pelo SESC de São Paulo [...] (SALGADO).

A participação de Salgado foi fundamental também na implantação de diversas formas de intervenção com a população idosa, no SESC. Ele criou em 1977, quando voltou da França, a Escola Aberta da Terceira Idade, a qual, embora baseada na 
Universidade de Toulose, somente realizava atividades com características teóricas, sem nenhuma atividade prática.

[...] era uma coisa assim: eram as universidades, os docentes, aquele excesso de horas que tinham, organizavam alguns cursos genéricos para idoso, ou, eventualmente, aceitavam alguns idosos naquelas disciplinas que não tinham preenchido o número de vagas, mas eram sempre porconvites, mas era puramente coisa teórica, mais na linha filosófica, na linha cultural, não tinha nenhuma atividade científica e não tinha nenhuma atividade prática, nem no sentido físico, nem no sentido da expressão). Quando nós chegamos, isso no SESC, montamos esse programa no SESC, chamamos "Escola Aberta da Terceira Idade", o sucesso da atividade física era tão, era tão forte, que todas as escolas implantadas tinham um segmento só de atividade corporal. Então, cada aluno que vinha, ele compunha o papel e escolhia, ele não era assim, pela experiência que eu vi. Ele tinha três áreas de concentração: práticas físicas, atividades de informação e atividades de expressão científica. Então, práticas físicas tinha: ginástica rítmica, ginástica corretiva, ginástica postural ... é, todo tipo de ginástica... yoga, que sempre foi uma coisa fantástica para a terceira idade... natação [..] (SALGADO).

Como vemos, Salgado e sua participação dentro e fora do SESC acabaram por refletir um momento em que o campo do idoso brasileiro começava a se organizar. Com o número crescente de idosos e a preocupação do poder público com o aumento dos índices de sobrevivência que começavam aparecer, definindo uma problemática social, o saber médico e seus preceitos paliativos surgem para amortizar tal situação. Agora os aposentados eram muitos. $\mathrm{O}$ que fazer com aqueles trabalhadores que agora chegam à velhice com tempo ocioso e utilizam-se dos recursos do governo durante muito mais tempo?

A incorporação do discurso gerontológico por parte do Estado reflete claramente a tentativa de controle do problema e principalmente caracteriza uma atitude que, apesar de necessária, ataca o efeito ao invés da causa, de uma política que não favorece o trabalhador, vetor maior da situação de miséria em que milhões se encontram. 
A pastoral do envelhecimento, prescrevendo um ativismo muitas vezes associado à prática de atividades físicas, teve sua gênese dentro desses vinte anos em que balizamos nosso estudo, fruto de diversas influências de diversos campos como o político, o social, o da saúde e o educacional.

\section{Considerações Finais}

A construção do campo do conhecimento das atividades físicas para idosos constituiu-se a partir do momento em que o campo do idoso teve sua delimitação construída no Brasil, entre os anos de 1960 e 1980. Sinergicamente vimos que campos com maior contribuição para que o campo do idoso emergisse de um processo que acompanhou uma inexorável transformação etária mundial foram os campos econômico, político, da saúde e educacional.

O envelhecimento da população, atrelado a uma reformulação do tempo do homem mediante o mundo do trabalho, exerceram sobre a sociedade uma pressão que culminou com medidas que alteraram paradigmaticamente a inserção social do idoso. Agora não se para mais de trabalhar para morrer. Esperar a morte já não se configura como uma característica dos "novos velhos", e a família não se apresenta mais como a única responsável por seus anciãos. O Estado começava a desenvolver formas de absorver seus velhos dentro de um processo fabril que os excluía, deixando-os à margem do sistema.

O saber médico apropriado pelo Estado logo reflete as primeiras tentativas de promover uma pastoral do envelhecimento. A saúde frente a um envelhecimento ativo parecia ser o norte que direcionaria as intervenções. 
O conceito multifatorial de saúde proposto pela Organização Mundial de Saúde em 1947 representava uma convergência de fatores que agora deveriam ser analisados em conjunto. A saúde não mais significava a ausência de doença e sim um somatório de situações que deveriam ser consideradas para uma avaliação da saúde do indivíduo. A atividade física começava a figurar como um meio para a busca de uma vida saudável.

O campo internacional que primeiramente defrontou-se com a transição etária construiu seu espaço desenvolvendo diversas ações que redimensionaram a vida do idoso. Esse campo foi o deflagrador para as iniciativas no Brasil, por isso, concordando com Bourdieu, compreender o primeiro facilitou a elucidação do segundo.

Nesse contexto, países como a França, os EUA e alguns países escandinavos como a Suécia e Noruega foram, dentre outros, os que primeiro desenvolveram preocupações para com o idoso. Assim, o campo do idoso no Brasil tornou-se muito refratário e, por conseguinte, autônomo, embora o capital específico produzido representasse a vanguarda sobre uma legislação para o idoso no Brasil.

Dessas novas preocupações, aliadas ao já existente trabalho de idosos realizado no SESC, as primeiras intervenções com os já idosos tiveram um impulso até então nunca visto. O SESC caracterizou-se como uma instituição pioneira frente às intervenções com idosos de uma forma mais democrática.

Dentro do campo interventivo, mesmo não tendo formação em educação física, Salgado deflagrou uma nova visão que acabou por se tornar hegemônica no trabalho físico envolvendo idosos dentro do SESC, disseminando a ideia da importância da atividade física para os já idosos e contribuindo para a construção de uma legislação específica. 
Concordamos com Bourdieu (1983) quando o autor ressalta que quanto maior a influência do agente social, maior será sua intenção na preservação ou conservação do sistema no qual ele é dominante. O capital específico é determinante para justificar tal afirmação a partir do momento em que entendemos a importância não só de Salgado, mas também de outros agentes sociais, que foram fundamentais para a construção do campo do qual detinham o conhecimento.

Dentro dessa nova tendência em promover uma velhice ativa, as atividades físicas começam a desenvolver-se nos centros sociais amparadas pela nova legislação, que agora percebia a necessidade de se equacionar a situação em que o idoso brasileiro se encontrava. As atividades de lazer associadas às atividades físicas são oferecidas à população idosa, que, mediante um panorama social mais afeto a uma pastoral do envelhecimento, que fomentava um ativismo em detrimento ao sedentarismo, permitia que o idoso praticasse exercícios físicos.

No final dos anos de 1950, Rocha realizou pesquisas com idosos, no intuito de avaliar a saúde do trabalhador brasileiro, baseadas em seus estudos na Suécia, porém acreditamos que os anos de 1960 foram propedêuticos em relação ao trabalho específico com idosos. Nessa linha de ação, em 1968, ao traduzir para o português o artigo retirado do comitê olímpico búlgaro, Ribeiro demonstrou uma nova preocupação dos intelectuais.

Não podemos deixar de ratificar que as atividades físicas para idosos foram incorporadas predominantemente pelas classes média e alta, que detêm condições de, na fase final da vida, reconhecer no exercício físico uma forma de potencializar suas chances na busca por uma melhor qualidade de vida. Esperar que indivíduos massacrados por uma vida de privações, exaustos por longas jornadas de trabalho que 
descompassaram sua idade biológica e cronológica desenvolvam tais atitudes é eximir o sistema da culpa e abandoná-los à própria sorte. Aliás, é o que vem acontecendo.

A velhice é o "somatório" de todas as idades. Se elas representaram momentos de extrema dificuldade, ao final da jornada as mazelas adquiridas ao longo da vida insurgem com mais força. A luta por uma vida com qualidade mostra-se fundamental para que os efeitos das atividades físicas sejam potencializados na velhice.

Assim, os idosos do futuro em nada se assemelharão aos de décadas atrás ou ainda aos de hoje. As transformações às quais a sociedade moderna submete seus contemporâneos serão determinantes na constituição de um quadro que, para os idosos do futuro (jovens de hoje), representará o habitus de nossa atualidade.

\section{REFERÊNCIAS}

ALVES JUNIOR, E. D. A pastoral do envelhecimento ativo. 2004. Tese (Doutorado) - Universidade Gama Filho, Rio de Janeiro, 2004.

BOURDIEU, P. O poder simbólico. Rio de Janeiro: Bertrand Brasil, 2005.

. Os usos sociais da ciência. São Paulo: UNESP, 2004 a.

A economia das trocas simbólicas. São Paulo: Perspectiva, 2004 b.

Questões de sociologia. Rio de Janeiro: Marco Zero, 1983.

BRASIL, Decreto-Lei n ${ }^{\circ}$ 9.853, de 13 de setembro de 1946. Diário Oficial da União, Rio de Janeiro, 13 set. 1946.

BRASIL. Ministério da Saúde. Conselho Nacional de Saúde. Diretrizes e normas regulamentadoras sobre pesquisa envolvendo seres humanos. Resolução 196. Brasília: CNS,1996.

CUNHA JUNIOR, C. F.; MELO, V. A. Uma conversa com Pedro Barros Silva. In: FARIA JUNIOR, A. G. de; FARINATTI, P. de T. V. Atividade física para idosos. Consensos e controvérsias. Rio de Janeiro: SPRINT, 1999. 
FARINATTI, P. de T. V.; FERREIRA, M. S. Saúde, promoção da saúde e educação física: conceitos, princípios e aplicações. Rio de Janeiro: EdUERJ, 2006.

FURTADO, E. S.; NOVAES, E. V. Um pouco da história d fisiologia do exercício e do LABOFISE. In: Aspectos diversos da medicina do exercício. Rio de Janeiro: Revinter, 2004. p. 33-40.

GAY, L. R. Educational research: competency for analysis and application. Columbus, Ohio: Cherles E. Merril Pub. Co., 1976.

HADDAD, E. G. de M. A ideologia da velhice. Rio de Janeiro: Cortez, 1986.

HOLLOSZY, J. O. Exercise, health, and aging: a need for more information. Medicine \& Science in Sports \& Exercise. v. 25, n. 5, may 1993.

MAGALHÃES, D. N. A invenção da velhice. Rio de Janeiro: Papagaio, 1989.

MELO, Victor Andrade de; ALVES JUNIOR, Edmundo de Drummond. Introdução ao lazer. Barueri: Manole, 2003.

RIBEIRO, T. F. Exercícios Físicos e Longevidade. In: Boletim Técnico Informativo do Ministério da Educação e Cultura. Rio de Janeiro: MEC, 1968.

ROCHA, M. L. Aspectos diversos da medicina do exercício. Rio de Janeiro: Revinter, 2004.

SERVIÇO SOCIAL DO COMÉRCIO (SESC). Trabalho social com idosos: 1963/1999 36 anos de realizações. São Paulo: SESC, 1999.

SOBRAL, S. B.. Proposta de ação pedagógica e prática de Educação Física centrada na pessoa idosa, com ênfase nas necessidades humanas básicas. 1986. Dissertação (Mestrado) - Universidade Federal do Rio de Janeiro, Rio de Janeiro, 1986.

TELLES, S. de C. C.; MOURÃO, L. Primórdios do movimento de teorização no campo da intervenção das atividades físicas para idosos: o artigo documento de Fernando Telles Ribeiro. In: CONGRESSO NACIONAL DE HISTÓRIA DO ESPORTE, LAZER, EDUCAÇÃO FÍSICA, 10, Curitiba. Anais... Curitiba, 2006.

UM BOM decálogo para alcançar a longevidade. Educação Physica, Rio de Janeiro, n. 13, p. 95, 1937.

WERNECK, Christianne L. G. Lazer, trabalho e educação: relações históricas, questões contemporâneas. Belo Horizonte: Editora UFMG, 2000. 


\section{Endereço dos Autores:}

Silvio de Cassio C. Telles

Escola de Educação Física e Desportos da UFRJ

Av. Carlos Chagas Filho, 540. Cidade Universitária

Rio de Janeiro - RJ - 21.941-599

Endereço Eletrônico: silviotelles@ufrj.br

Rômulo M. Reis

Endereço Eletrônico: romulomreis@bol.com.br

Edmundo de Drummond Alves Júnior

Rua Assunção 162, apt. 203 Bairro Botafogo

Rio de Janeiro - RJ - 22.251-030

Endereço Eletrônico: edmundodrummond@uol.com.br

Ludmila Mourão

Rua Mário Pederneiras no 4, Apt. 204 Bairro Humaitá

Rio de Janeiro - RJ - 22.261-020

Endereço Eletrônico: ludmila.mourao@terra.com.br 